\title{
Review
}

\section{Systematic review and meta-analysis on the effect of obesity on recurrence after laparoscopic anti-reflux surgery ${ }^{\text {is }}$}

\author{
Yasir Bashir ${ }^{a, *}$, Hazel Ní Chonchubhair ${ }^{a}$, Sinead N. Duggan ${ }^{a}$, \\ Robert Memba ${ }^{a}$, Qurat ul Ain ${ }^{b}$, Anne Murphy ${ }^{c}$, Jean McMahon ${ }^{c}$, \\ Paul F. Ridgway ${ }^{a}$, Kevin C. Conlon ${ }^{a}$ \\ a Professorial Surgical Unit, Department of Surgery, The University of Dublin Trinity College, Tallaght Hospital, \\ Dublin, Ireland \\ ${ }^{\mathrm{b}}$ Department of Surgery, Naas General Hospital, County Kildare, Ireland \\ c Tallaght Hospital Library, Tallaght Hospital, Dublin, Ireland
}

\section{A R T I C L E I N F O}

Article history:

Received 24 November 2017

Received in revised form

31 January 2018

Accepted 4 May 2018

Available online xxx

Keywords:

GORD

LARS

Meta-analysis

Obesity

Recurrence

Systematic review

\begin{abstract}
A B S T R A C T
Background \& aims: Laparoscopic anti-reflux surgery (LARS) aims to provide relief from gastroesophageal reflux disease (GORD). With increase in the prevalence of obesity, there is a concurrent increase in obese patients requiring LARS. In addition to being a more technically difficult procedure, there is conflicting evidence regarding the effectiveness of LARS in obese patients. We performed a systematic review and meta-analysis to compare the outcomes of LARS in obese versus non-obese patients.

Methods: Articles on the effects of obesity on LARS were identified from Ovid Medline, EMBASE and the Cochrane Library databases up to 30th of November 2016. Two independent searches were conducted. Data were extracted independently by two researchers. The primary outcome was recurrence, whilst the secondary outcome was operative time. Pooled data were statistically analysed using forest and funnel plots.

Results: Twelve studies (3346 patients) met the inclusion criteria, with 923 patients in the obese group and 2423 patients in the non-obese group. Based on a random effects model, there was a risk ratio of 1.36 (95\% CI 1.08-1.72, $\mathrm{p}=0.009$ ), if studies reporting recurrence objectively are analysed risk ratio of 1.53 (95\% CI 1.01-2.32, p = 0.05) showing 53\% increased risk of recurrence for obese patients. Using a random effects model, the difference in operative time was 13.94 min (95\% confidence interval (CI) 9.33-18.55, p < 0.0001), showing an increased operative time for obese patients.

Conclusion: A meta-analysis of 12 studies showed that there was greater recurrence of GORD symptoms and longer operative time relating to LARS in obese patients compared to non-obese patients.

(C) 2018 Royal College of Surgeons of Edinburgh (Scottish charity number SC005317) and Royal College of Surgeons in Ireland. Published by Elsevier Ltd. All rights reserved.
\end{abstract}

\footnotetext{
4 The manuscript was presented as Oral presentation in "Sir Peter Freyer Meeting Galway" in 2017 and also selected for Poster presentation in "EAES London" 2018.

* Corresponding author. Department of Surgery, Room 1.40, Trinity Centre of Learning and Development, Tallaght Hospital, Dublin 24, Ireland.

E-mail address: ybashir@tcd.ie (Y. Bashir). https://doi.org/10.1016/j.surge.2018.05.001

1479-666X/@ 2018 Royal College of Surgeons of Edinburgh (Scottish charity number SC005317) and Royal College of Surgeons in Ireland. Published by Elsevier Ltd. All rights reserved.
} 


\section{Introduction}

Obesity is increasing worldwide at an alarming rate. In the US, obesity doubled between 1980 and 2002, while the number of overweight tripled during the same period. ${ }^{1}$ According to the 2008 World Health Organisation (WHO) report 50\% of both men and women in the Europe were overweight, and roughly $20 \%$ of men and $23 \%$ women were obese. These data were considerably higher than in a WHO report published in 2005, with $23.2 \%$ of whole world population being overweight and $9.8 \%$ obese.

Gastroesophageal reflux disease (GORD) is a reasonably common disease. About $20 \%$ of the adult population in western countries suffer from GORD. ${ }^{3,4}$ The symptoms of GORD include heartburn, globus sensation, epigastric pain, chest pain, dyspepsia, and dysphagia. ${ }^{3}$ The complications of GORD vary from reflux oesophagitis, erosive oesophagitis, Schatzki ring formation, Barrett's oesophagus ${ }^{5}$ and adenocarcinoma. ${ }^{6,7}$ Medical management is the cornerstone of the initial management, following life style modifications. PPI therapy has shown remarkable long-term safety ${ }^{8}$ and is the most commonly prescribed medication.

Although it is still controversial as to whether obesity predisposes people to gastroesophageal reflux disease, ${ }^{9-11}$ with such a high prevalence of obesity, surgeons are required to treat patients categorised as obese with anti-reflux surgery. Since the availability of laparoscopic anti-reflux surgery (LARS), the threshold for offering surgery to patients with GORD has changed. LARS is extremely effective in controlling GORD symptoms. Indications for LARS include persistent or recurrent acid reflux after acid suppression therapy, increased oesophageal acid exposure, and mechanically defective lower oesophageal sphincter on manometry. ${ }^{12}$ Relative indications include non-compliant patients, patients on very high doses of medication and patients too young for lifetime medical treatment. ${ }^{13}$ Multiple studies showed that surgical approach is superior to medical management alone for refractory cases of the gastroesophageal reflux disease. ${ }^{14,15}$

Laparoscopic anti-reflux surgery (LARS) includes laparoscopic Nissen fundoplication (LNF), which is considered as gold standard surgery for GORD. It involves using a wrap of fundus of stomach, which is passed through a space created behind oesophagus, dividing short gastric arteries near the fundus to make it mobile enough to be used as a wrap, and stitching this to the other side making a $360^{\circ}$ circle around the lower oesophagus. The long-term effectiveness of LNF is reported in several studies. ${ }^{16-18}$ Laparoscopic toupet (LT) is a $270^{\circ}$ posterior wrap, which is commonly carried out in patients with symptoms of dysphagia to avoid exaggeration of postoperative dysphagia. Studies have shown it to be as effective as LNF. ${ }^{19,20}$ Other modifications involve $180^{\circ}$ anterior and posterior wraps, and are all categorised as LARS.

It is unclear if LARS is as effective in obese patients as it is in non-obese patients. ${ }^{21,22}$ Moreover, it is not known if the surgery is more complex or difficult for obese patients. With ever increasing obesity rates and controversial results about the effect of obesity on the recurrence rates, we felt a need to clarify the impact of obesity on the success of anti-reflux surgery.

\section{Methods}

\section{Protocol and registration}

The Preferred Reporting Items for Systematic Reviews and Meta-Analyses (PRISMA) ${ }^{23}$ was used for reporting. The study was registered with International Prospective Registry for Systematic reviews (PROSPRO), registration number CRD42016050601.

\section{Eligibility criteria}

The PICO model was used to devise the search criteria, defined in detail in Table 1. We included studies which included data on both obese and non-obese patients. Specifically, we included patients who were obese (body mass index (BMI) $\geq 30 \mathrm{~kg} / \mathrm{m}^{2}$ ), ${ }^{24}$ with acid reflux disease, and who underwent LARS for relief of GORD (first-time surgery only). As a comparison group, we recorded the details of non-obese patients (BMI $<30 \mathrm{~kg} / \mathrm{m}^{2}$ ) with acid reflux disease, who underwent LARS for relief of GORD. The outcomes of interest were recurrence (the primary outcome) and operative time (the secondary outcome). Both prospective and retrospective studies were included. Articles missing primary outcome, expert opinions, reviews, studies on patients undergoing LARS for the second or subsequent time, data on patients under 18 years, and conference proceedings that later resulted in full research were excluded.

\begin{tabular}{|c|c|}
\hline PICOS & Inclusion and Exclusion criteria \\
\hline Patient & $\begin{array}{l}\text { Incl: Patient categorised as obese by WHO } \\
\text { criteria (BMI > 30), suffering from GERD. } \\
\text { Excl: Patients under the age of } 18 \text {. }\end{array}$ \\
\hline Intervention & $\begin{array}{l}\text { Incl: Laparoscopic Anti-Reflux Surgery (Lap } \\
\text { Nissen fundoplication, Lap Toupet, Lap } \\
\text { anterior/posterior } 180^{\circ} \text { wrap) } \\
\text { Excl: Redo surgery, Open Surgery, Bariatric } \\
\text { procedures. }\end{array}$ \\
\hline Comparison & $\begin{array}{l}\text { Incl: Patient categorised as non-obese by } \\
\text { WHO criteria (BMI<30), suffering from GERD. } \\
\text { Excl: Patients under the age of } 18 \text {. }\end{array}$ \\
\hline Outcome & $\begin{array}{l}\text { Primary outcome: Recurrence (symptomatic } \\
\text { recurrence) } \\
\text { Secondary outcome: Operative time }\end{array}$ \\
\hline Study Design & $\begin{array}{l}\text { Incl: Randomized controlled trials, } \\
\text { controlled trials (eg, nonrandomized, } \\
\text { historical controls), Observational studies, } \\
\text { Conference proceedings with sufficient data } \\
\text { available were included(if became full article } \\
\text { afterwards only full article is include to } \\
\text { prevent duplication of data) } \\
\text { No restriction of language or region was } \\
\text { applied. } \\
\text { Excl: Animal studies were excluded }\end{array}$ \\
\hline
\end{tabular}




\section{Information sources}

Search strategy was devised by researcher (Y.B) and the librarians (A.M \& J.M). Two independent searches were undertaken in November 2016 on the bibliographic databases Ovid MEDLINE (1946 to November 2016); EMBASE (1980 to November 2016) and the Cochrane Central Register of Controlled Trials (CENTRAL) by researcher and librarians. All studies on obese patients with acid reflux disease were included. Studies involving obese patients who underwent laparoscopic antireflux surgery were included, and studies for the comparative group involving normal and overweight patients who underwent laparoscopic anti-reflux surgery were included. The primary outcome was defined as recurrence of reflux and the secondary outcome was operative time. Studies were not limited by study type in the search strategy.

\section{Search strategies}

Search strategy was developed for Ovid Medline and adapted for searching CENTRAL. In addition, the researchers translated the strategy for use in EMBASE. All strategies were structured using the PICO model and used a MeSH or EMTREE terms as appropriate, combined with keywords, to identify published studies about the effect of obesity on patients undergoing laparoscopic anti-reflux surgery. Subject headings and keywords relating to obesity; and gastroesophageal reflux; and laparoscopy, fundoplication, Nissen, Toupet or wrap; and recurrence, hiatal hernia or GORD were searched. Language, geographical and date restrictions were not applied. Study type limits were not applied. Additional studies were identified by reference searching.

\section{Study selection}

After duplicates removed, all the studies identified in the search were screened independently by two reviewers (YB and RM), using article titles and abstracts against predefined inclusion and exclusion criteria. If there was any conflict about a study, it was resolved with consensus. Conference proceedings were included if they met the inclusion criteria and had the required information. The reviewers were not blinded regarding the authors or the institutions of the studies. In the case of missing data, corresponding authors were contacted by email.

\section{Data extraction and items}

Data were extracted by two independent researchers (YB and QU) using predetermined data extraction form. The initial part included general information about the article and assessed whether it contained the primary and secondary outcomes of interest. Studies containing at least the primary outcome (recurrence) were included. 'Recurrence' was defined as "recurrence of the reflux symptoms". Operative time (secondary outcome) was measured in minutes.

\section{Quality assessment and risk of bias}

The quality of each individual study was assessed independently by two reviewers (YB and RM), using the
Newcastle-Ottawa Scale, ${ }^{25}$ which employs a star scoring system for the quality assessment of studies. A total of 9 stars can be awarded to a study. A study can be awarded a maximum of 4 for selection, 3 for outcome and maximum of 2 stars for comparability. Studies were categorised as low, moderate and high quality depending on the number of stars; $0-3$ were low quality, 4-6 were medium quality and 7-9 were high quality.

\section{Summary measures and synthesis of results}

We calculated risk ratio and confidence interval (CI) for the primary outcome, while difference in means and CI was calculated for the secondary outcome using meta-analysis software Review Manager (ReuMan) Version 5.3 26,27 (Copenhagen: The Nordic COCHRANE Collaboration, 2014). A random effects model was used which gives us a more conservative estimate of the effect of obesity on LARS. Studies which reported recurrence after objective assessment by investigations were analysed separately to have more critical view of effect of obesity on recurrence after LARS. Forest Plots and Funnel Plots were also created using this software. Data for recurrence were also analysed for Pearson Chi-Square using SPSS version 23 (IBM corporation USA licenced 1989, 2015).

Using the above-mentioned software, a pooled estimate of recurrence and operative time from all the included studies was calculated. Statistical heterogeneity among the studies was calculated using $\mathrm{I}^{2}$ (values ranged between $0 \%$ and $100 \%$, with values closer to $0 \%$ indicating less heterogeneity). $I^{2}$ describes the percentage of variation among studies caused by heterogeneity rather than by chance. A P-value of less than 0.05 was considered significant, where appropriate.

\section{Results}

\section{Study selection}

The number of articles found through electronic search of Ovid Medline, EMBASE and COCHRANE library were 5191. Further 44 articles were found through other means, which included hand searching through the bibliography of relevant articles. The total after adding both was 5235. After duplicates were removed, the number of articles was 4282. Screening of these articles was done using title and abstract of the articles, removing another 4257, leaving 25 articles to be assessed with full text. The full text of 25 articles was studied in detail and 12 studies were included in our qualitative and quantitative analysis. Five studies ${ }^{28-32}$ who reported recurrence depending on objective assessment were analysed separately as well to have more accurate measurement of effect of obesity on recurrence after LARS. The studies which were excluded after reviewing full text included $\operatorname{six}^{21,33-36}$ which were missing the primary outcome or where the primary outcome could not be calculated from the available data. Two studies ${ }^{37,38}$ grouped the patients according to BMI, but the categorisation differed from ours, and therefore the data were not amenable to metaanalysis. One study ${ }^{39}$ categorised patients according to weight only, and data provided were not enough to calculate BMI. One article $^{40}$ was expert opinion and contained no original data. Another divided patient according to results, and therefore 
data could not be extracted. One conference presentation ${ }^{41}$ later became a full publication ${ }^{30}$ which was included. One paper $^{42}$ had only obese patients, so was excluded. See Fig. 1 for search summary.

\section{Study characteristics}

The characteristics of the studies included are detailed in Table 2. Four studies were from the USA, ${ }^{29,30,43,44}$ two from Europe, ${ }^{45,46}$ two Australia, ${ }^{2,47}$ two Asia ${ }^{28,31}$ and one each from Canada $^{32}$ and Brazil. ${ }^{48}$ All twelve studies were available in the English Language. The number of patients in the studies ranged from $16^{48}$ to $1000 .^{28}$ Overall, 3346 patients underwent laparoscopic anti-reflux surgery for gastroesophageal reflux disease. A total of 2423 patients were in non-obese and 923 patients were in the obese group. Follow-up ranged from 12 months ${ }^{44,45,48}$ to 90 months. ${ }^{22}$ Laparoscopic Nissen Fundoplication (LNF) was the most favoured procedure, done in every study, followed by Laparoscopic Toupet (LT), which was done in four studies. ${ }^{22,28,31,45}$

Seven studies ${ }^{22,43-48}$ defined recurrence as 'recurrence of symptoms necessitating medication (PPI) use', while the remaining five, ${ }^{28-32}$ included 'radiological and endoscopic investigation after symptom recurrence' as part of their definition of recurrence. Eight of the studies were prospective $22,28-32,43,47$ while four were retrospective. ${ }^{44-46,48}$ This is summarised in Table 2 .

\section{Assessment of studies}

Study quality was assessed using Newcastle-Ottawa Scale. All studies scored seven stars or more (of a possible 9 stars) on


Total $(n=5,235)$

Records after duplicates removed $(n=4,282)$

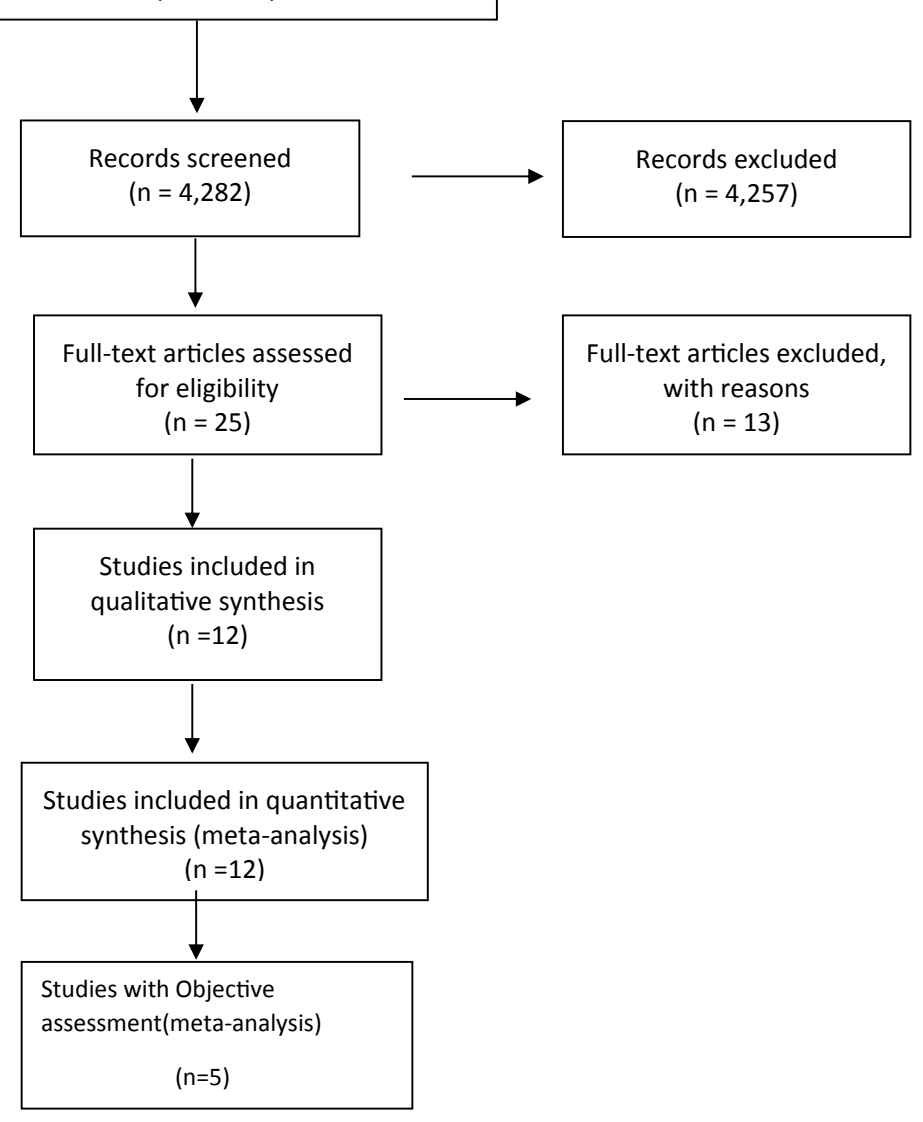

Fig. 1 - PRISMA flowchart, Preferred Reporting Items for Systematic Reviews and Meta-Analyses. This summarize the selection of studies in meta-analysis. 
Table 2 - Summary of all the studies included in systematic review and meta-analysis. $\mathrm{Ob}=\mathrm{Obese}$ patients and Nob $=$ non-obese patients in each study

NOS = Newcastle Ottawa scale, BMI = body mass index, LNF = Laparoscopic Nissen fundoplication, LT = Laparoscopic Toupet, AF = Anterior fundoplication. Follow up is recorded in months, recurrence is number of patients with failure of LARS and operative time in minutes. * is number of stars according to Newcastle Ottawa scale.

\begin{tabular}{|c|c|c|c|c|c|c|c|c|c|c|c|c|c|}
\hline & $\begin{array}{l}\text { Data } \\
\text { recorded }\end{array}$ & Country & $\begin{array}{c}\text { Patients } \\
\mathrm{n}=\end{array}$ & BMI & Evidence & Procedures & Sex & $\begin{array}{l}\text { Follow } \\
\text { up }\end{array}$ & Recurrence & $\begin{array}{l}\text { Definition of } \\
\text { recurrence }\end{array}$ & Operative time & $\begin{array}{l}\text { Effect of } \\
\text { obesity on } \\
\text { LARS }\end{array}$ & NOS \\
\hline $\begin{array}{l}\text { Tekin K et al. } \\
2012 \text { Surg Endoscopy }\end{array}$ & Prospective & Turkey & $\mathrm{n}=1000$ & $\begin{array}{l}\text { Nob }=868 \\
\mathrm{Ob}=132\end{array}$ & 2 & $\begin{array}{l}\mathrm{LNF}=684 \\
\mathrm{LT}=316\end{array}$ & $\begin{array}{l}M=613 \\
F=387\end{array}$ & $53.33 \mathrm{~m}$ & $\begin{array}{l}\mathrm{Nob}=17 \\
\mathrm{Ob}=3\end{array}$ & $\begin{array}{l}\text { Symptomatic than } \\
\text { ph and endoscopy }\end{array}$ & $\begin{array}{l}\text { Nob }=48.05 \pm 21.20 \\
O=61.33 \pm 28.47\end{array}$ & Adverse effect & $8^{*}$ \\
\hline $\begin{array}{l}\text { Fraser J et al. } \\
2001 \text { Disease of Esop }\end{array}$ & Prospective & Australia & $\mathrm{n}=194$ & $\begin{array}{l}\mathrm{Nob}=128 \\
\mathrm{Ob}=66\end{array}$ & 2 & LNF & $\begin{array}{l}M=117 \\
F=77\end{array}$ & $38.4 \mathrm{~m}$ & $\begin{array}{l}\text { Nob }=17 \\
O=10\end{array}$ & $\begin{array}{l}\text { Symptomatic } \\
\text { (heartburn) QOL }\end{array}$ & $\begin{array}{l}\text { Nob }=66 \pm 9 \\
O=73 \pm 8\end{array}$ & No effect & $7^{*}$ \\
\hline $\begin{array}{l}\text { Chisholm JA et al. } \\
2009 \text { J Gastrointestinal } \\
\text { Surg }\end{array}$ & Prospective & Australia & $\mathrm{n}=481$ & $\begin{array}{l}\text { Nob }=311 \\
\mathrm{Ob}=170\end{array}$ & 2 & $\begin{array}{l}\mathrm{LNF}=322 \\
\mathrm{AF}=148 \\
\mathrm{LT}=11\end{array}$ & $\begin{array}{l}M=278 \\
F=203\end{array}$ & $90 \mathrm{~m}$ & $\begin{array}{l}\text { Nob }=47 \\
O=10\end{array}$ & $\begin{array}{l}\text { Symptomatic(heartburn) } \\
\text { QOL }\end{array}$ & $\begin{array}{l}\text { Nob }=75 \pm 7 \\
\mathrm{O}=86 \pm 8\end{array}$ & No effect & $8^{*}$ \\
\hline $\begin{array}{l}\text { Winslow ER et al. } \\
2003 \text { Surg Endoscopy }\end{array}$ & Prospective & USA & $\mathrm{n}=505$ & $\begin{array}{l}\text { Nob }=292 \\
\mathrm{Ob}=212\end{array}$ & 2 & LNF & - & $\begin{array}{l}35 \pm \\
25 \mathrm{~m}\end{array}$ & $\begin{array}{l}\mathrm{Nob}=24 \\
\mathrm{O}=21\end{array}$ & $\begin{array}{l}\text { Ba swallow, ph and } \\
\text { endoscopy }\end{array}$ & $\begin{array}{l}\text { Nob }=115 \pm 42 \\
O=137 \pm 55\end{array}$ & No effect & $8^{*}$ \\
\hline $\begin{array}{l}\text { Perez AR et al. } \\
2001 \text { Surg Endoscopy }\end{array}$ & Prospective & USA & $\mathrm{n}=187$ & $\begin{array}{l}\text { Nob }=152 \\
\mathrm{Ob}=35\end{array}$ & 2 & LNF & $\begin{array}{l}M=99 \\
F=88\end{array}$ & $37 \mathrm{~m}$ & $\begin{array}{l}\text { Nob }=8 \\
O=8\end{array}$ & $\begin{array}{l}\text { Symptomatic than ph } \\
\text { or Ba swallow }\end{array}$ & $\begin{array}{l}\text { Nob }=144 \pm 47 \\
O=152 \pm 35\end{array}$ & Adverse effect & $8^{*}$ \\
\hline $\begin{array}{l}\text { Ng VV et al. } \\
2007 \text { Ann R Coll Surg } \\
\text { Engl }\end{array}$ & Retrospective & UK & $\mathrm{n}=366$ & $\begin{array}{l}\text { Nob }=292 \\
\mathrm{Ob}=74\end{array}$ & 3 & $\begin{array}{l}\mathrm{LNF}=292 \\
\mathrm{LT}=73\end{array}$ & $\begin{array}{l}M=237 \\
F=129\end{array}$ & $12 \mathrm{~m}$ & $\begin{array}{l}\text { Nob }=8 \\
\mathrm{O}=2\end{array}$ & $\begin{array}{l}\text { Need for medication } \\
\text { QOL }\end{array}$ & $\begin{array}{l}\text { Nob }=81 \pm 50 \\
O=93 \pm 39\end{array}$ & No effect & $7^{*}$ \\
\hline $\begin{array}{l}\text { Tsuboi K et al. } \\
2009 \text { Esophagus }\end{array}$ & Prospective & Japan & $\mathrm{n}=145$ & $\begin{array}{l}\text { Nob }=135 \\
\mathrm{Ob}=10\end{array}$ & 2 & $\begin{array}{l}\mathrm{LNF}=63 \\
\mathrm{LT}=73 \\
\mathrm{CN}=9\end{array}$ & $\begin{array}{l}M=93 \\
F=52\end{array}$ & $77 \mathrm{~m}$ & $\begin{array}{l}\text { Nob }=14 \\
\mathrm{O}=1\end{array}$ & Endoscopy & $\begin{array}{l}\text { Nob }=152.8 \pm 47.8 \\
O=181.9 \pm 19.3\end{array}$ & No effect & $7^{*}$ \\
\hline \multirow[t]{2}{*}{$\begin{array}{l}\text { S McNatt et al. } \\
2000 \text { Gastroenterology }\end{array}$} & Prospective & USA & $\mathrm{n}=74$ & $\begin{array}{l}\text { Nob }=37 \\
\mathrm{Ob}=37\end{array}$ & 2 & LNF & - & $20.4 \mathrm{~m}$ & $\begin{array}{l}\text { Nob }=13 \\
\mathrm{O}=23\end{array}$ & $\begin{array}{l}\text { Symptomatic } \\
\text { Need med }\end{array}$ & $\begin{array}{l}\text { Nob }=161 \pm 5 \\
\mathrm{O}=183.9 \pm 5\end{array}$ & No effect & $7^{*}$ \\
\hline & $\begin{array}{l}\text { Data } \\
\text { recorded }\end{array}$ & Country & $\begin{array}{l}\text { Patients } \\
\mathrm{n}=\end{array}$ & BMI & Evidence & Procedures & Sex & $\begin{array}{l}\text { Follow } \\
\text { up }\end{array}$ & Recurrence & Definition of recurrence & Operative time & Outcome & NOS \\
\hline $\begin{array}{l}\text { Kappaz G.T et al. } \\
2010 \text { Disease of } \\
\text { Oesophagus }\end{array}$ & Retrospective & Brazil & $\mathrm{n}=16$ & $\begin{array}{l}\mathrm{Nob}=10 \\
\mathrm{Ob}=6\end{array}$ & 3 & LNF & - & $12 \mathrm{~m}$ & $\begin{array}{l}\text { Nob }=6 \\
\mathrm{O}=5\end{array}$ & QOL and use of PPI & - & Adverse effect & $7^{*}$ \\
\hline $\begin{array}{l}\text { Anvari M et al. } \\
2007 \text { Surg Endoscopy }\end{array}$ & Prospective & Canada & $\mathrm{n}=140$ & $\begin{array}{l}\text { Nob }=70 \\
\mathrm{Ob}=69\end{array}$ & 1 & LNF & - & $\begin{array}{l}41.6 \pm \\
2.9 \mathrm{~m}\end{array}$ & $\begin{array}{l}\text { Nob }=0 \\
\mathrm{O}=1\end{array}$ & Symptomatic than ph & $\begin{array}{l}\text { Nob }=50 \pm 2.1 \\
O=55.9 \pm 2.3\end{array}$ & No effect & $9^{*}$ \\
\hline $\begin{array}{l}\text { Hahnloser D et al. } \\
2002 \text { Surg Endoscopy }\end{array}$ & Retrospective & Switzerland & $\mathrm{n}=126$ & $\begin{array}{l}\text { Nob }=75 \\
\mathrm{Ob}=51\end{array}$ & 3 & LNF & - & $42 \mathrm{~m}$ & $\begin{array}{l}\text { Nob }=4 \\
\mathrm{O}=3\end{array}$ & Symptomatic QOL & - & Adverse effect & $7^{*}$ \\
\hline $\begin{array}{l}\text { Kanji A et al. } \\
2013 \text { Archives of } \\
\text { Surgery(S) }\end{array}$ & Retrospective & USA & $\mathrm{n}=114$ & $\begin{array}{l}\text { Nob }=53 \\
\text { Ob }=61\end{array}$ & 3 & LNF & - & $12 \mathrm{~m}$ & $\begin{array}{l}\text { Nob }=5 \\
\mathrm{O}=15\end{array}$ & Reflux and PPI use QOL & $\begin{array}{l}\text { Nob }=100 \pm 27.9 \\
O=117 \pm 31.9\end{array}$ & No effect & $7^{*}$ \\
\hline
\end{tabular}


this scale, so were deemed to be high quality studies. They ranged between seven stars ${ }^{31,43-48}$ and nine stars. ${ }^{32}$ There was $100 \%$ agreement on quality of the studies between the two reviewers (YB and $\mathrm{RM}$ ).

\section{Results of studies}

Eight of 12 studies $^{22,29,31,32,43-45,47}$ reported that there was no statistically significant adverse effect of obesity on recurrence of LARS. Four ${ }^{28,30,46,48}$ suggested significant adverse effect of obesity on recurrence after LARS. Numbers of patients experiencing recurrence ranged from 1 to $23^{32}$ for obese patients and 0 to $47^{22,32}$ for non-obese patients. Studies exhibited a huge variation in operative time, ranging from mean (standard deviation, SD) 48.05(21.2) $\min ^{28}$ to $161(5) \mathrm{min}^{43}$ for non-obese and 55.9(2.3) $\mathrm{min}^{32}$ to $181.9(19.3) \mathrm{min}^{31}$ for obese patients. Each individual study reported that operative times for obese patients were statistically longer than that of nonobese patients.

\section{Synthesis of results}

The total pooled number of patients in all the studies was 3346, specifically 923 obese patients and 2423 non-obese patients. Based on a random effect model, the overall risk ratio for recurrence after LARS in obese versus non-obese patients was 1.36 (95\% CI 1.08-1.72) (Fig. 2), with non-obese patients having less recurrence (see Fig. 2). When studies which reported recurrence based on objective assessment were analysed separately, there were 1517 patients in non-obese group and 458 in obese group. Risk ratio was $1.53(95 \%$ CI 1.01-2.32) based on fixed effect model showing more clearly that there is a definitely an increased risk of recurrence of GORD after LARS in obese patients as compared to non-obese patients (Fig. 3).
There was minimal heterogeneity among the studies for recurrence $\left(I^{2}=0 \%\right)$. When included in the funnel plot (Fig. 4) most of the studies were very close to the overall result of the meta-analysis. Smaller studies are towards the bottom of the funnel plot while larger studies are towards the top of the inverted funnel. Using a random effect model, the mean difference in operative time between obese and non-obese patients was $13.94 \mathrm{~min}$ (95\% CI 9.33-18.55). Two studies did not have secondary outcomes. ${ }^{46,48}$ There was significant heterogeneity among the studies with $I^{2}=96 \%$. Figure 5 shows that obese patients had significantly longer operative times that non-obese patients. A funnel plot of the operative time shows larger studies towards the top of inverted funnel (Fig. 6).

\section{Additional analysis}

Additional analysis of recurrence in obese versus non-obese patients who underwent LARS, was done. A chi-square test showed that there was statistically significant relationship between obesity and recurrence $(p<0.005)$.

\section{Discussion}

To our knowledge, this is the first meta-analysis to be conducted on the effect of obesity on laparoscopic anti-reflux surgery (LARS) registered with PROSPERO and online since 1/ 11/2016 with registration number CRD42016050601. There are enormous difference of opinion on the effect of obesity on recurrence after LARS, varying from adverse effects ${ }^{28,30,46,48}$ to no effects $22,29,31,32,43-45$ on outcome being reported. While there were arguable results for recurrence among the studies, there was consensus between the studies indicating that

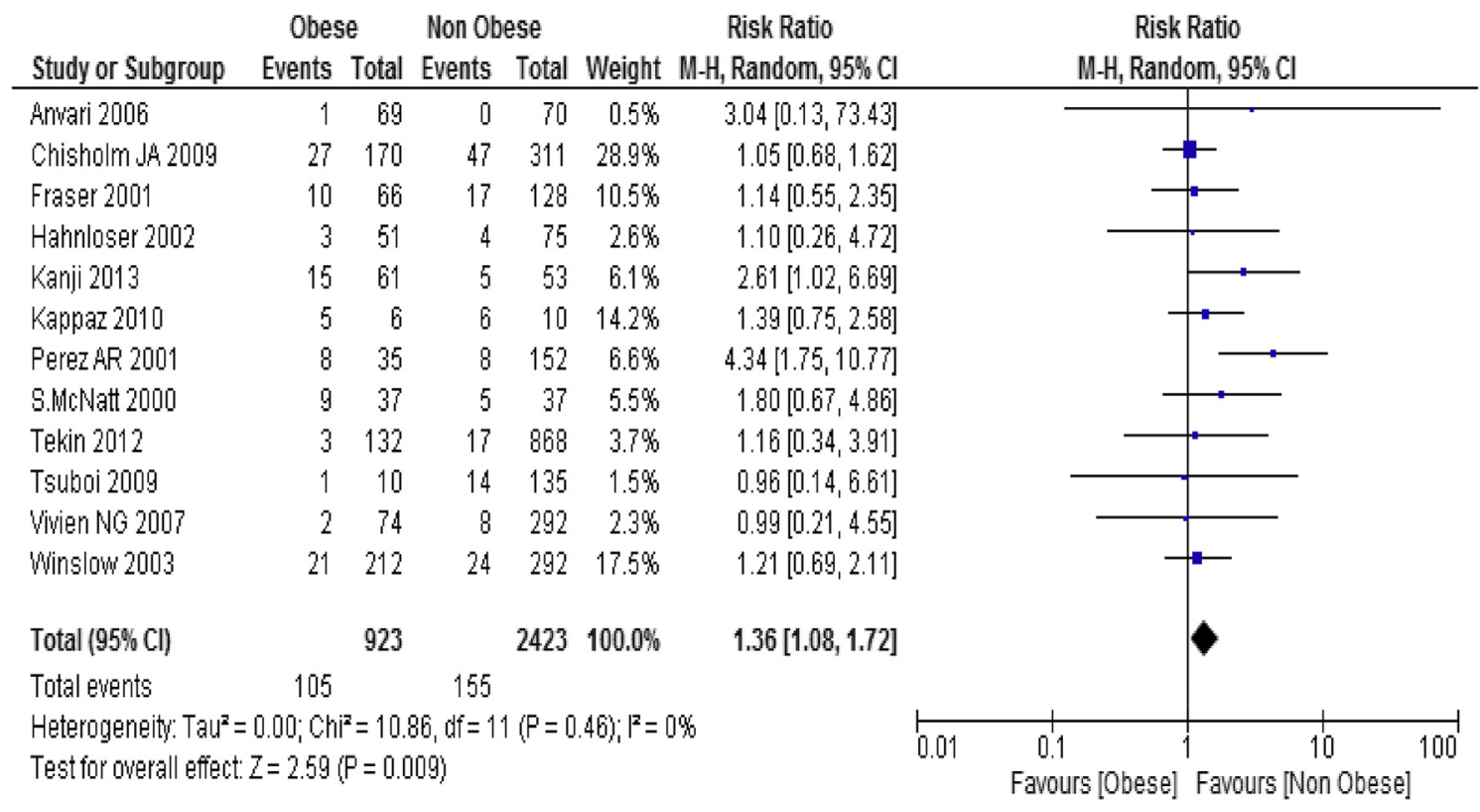

Fig. 2 - Forest Plot of the recurrence after Laparoscopic Antireflux surgery in Obese Vs Non-Obese patients. Risk Ratio of 1.36 (95\% confidence interval (CI) $1.08-1.72)$ with minimal heterogeneity $I^{2}=0 \%$. Effect size $Z=2.59$ which is significant $(p=0.009)$. 


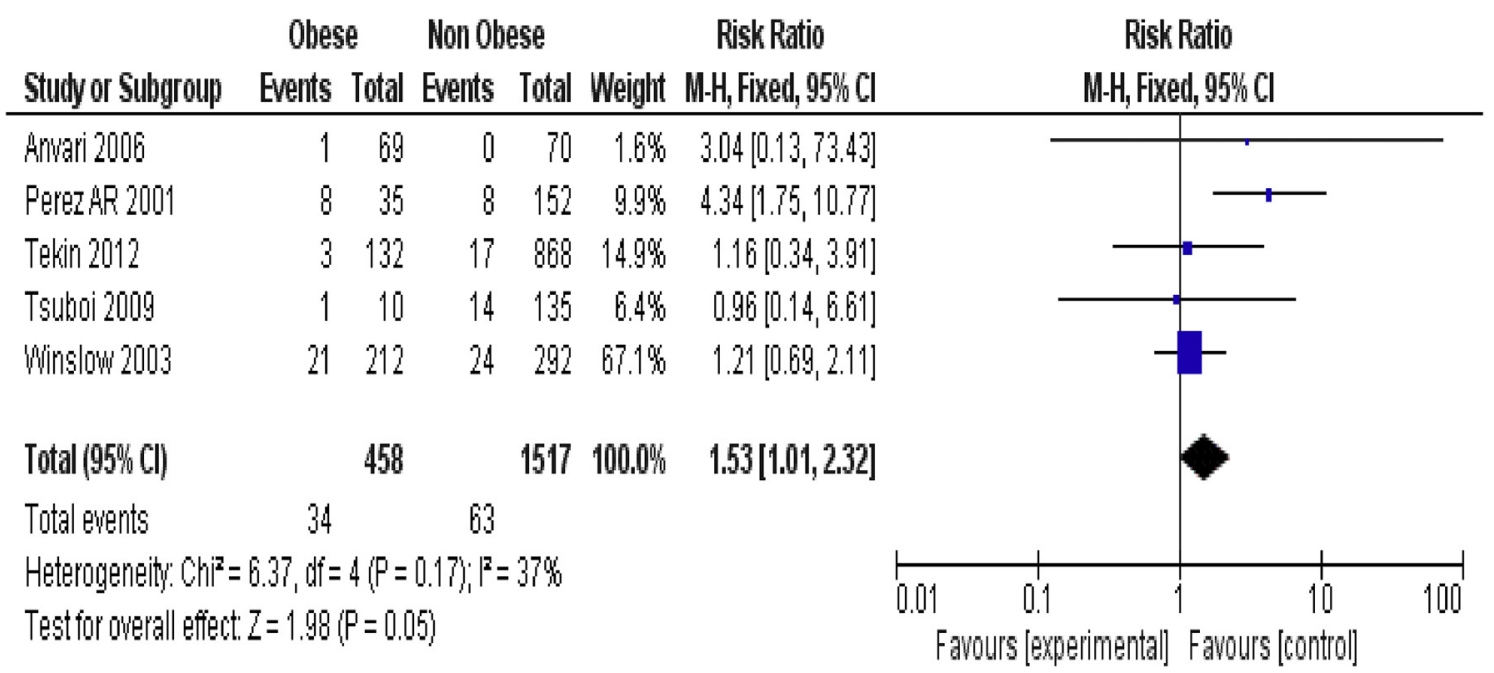

Fig. 3 - Forest Plot of the recurrence after Laparoscopic Antireflux surgery in Obese Vs Non-Obese patients objectively assessed. Risk Ratio of 1.53 (95\% confidence interval (CI) 1.01-2.32) with heterogeneity $I^{2}=37 \%$. Effect size $Z=1.98$ which is significant ( $p=0.05)$.

surgery for obese patients is more challenging, as can be seen by the longer operative time for the obese patients.

Perez et al. ${ }^{30}$ were the first to suggest that obesity adversely effects LARS. They were of the opinion that thoracic approach would bring better results, however their results showed that obesity negatively effects both the procedures. Later, multiple studies were done to examine the effect of obesity on LARS with conflicting results.

We divided the patients into obese and non-obese patients, using WHO criteria. ${ }^{49}$ Operating on obese patients is technically more difficult, chances of having perioperative complication are higher and the more risk is associated with surgical procedures in obese patients. ${ }^{50-53}$ Although LARS has proven benefits for patients with GORD, it is important to establish if there is long term relief of symptoms.

This meta-analysis determines that obesity increases the chance of recurrence of symptoms of GORD after LARS. Additionally, our results show that obesity is associated with longer operative time in laparoscopic anti-reflux surgery. It is previously shown by multiple studies that longer operative time is associated with increased infection rates and other complications in laparoscopic surgery. ${ }^{54,55}$

Multiple factors are thought to be responsible in the pathophysiology of GORD in obese. Hiatal hernias are more

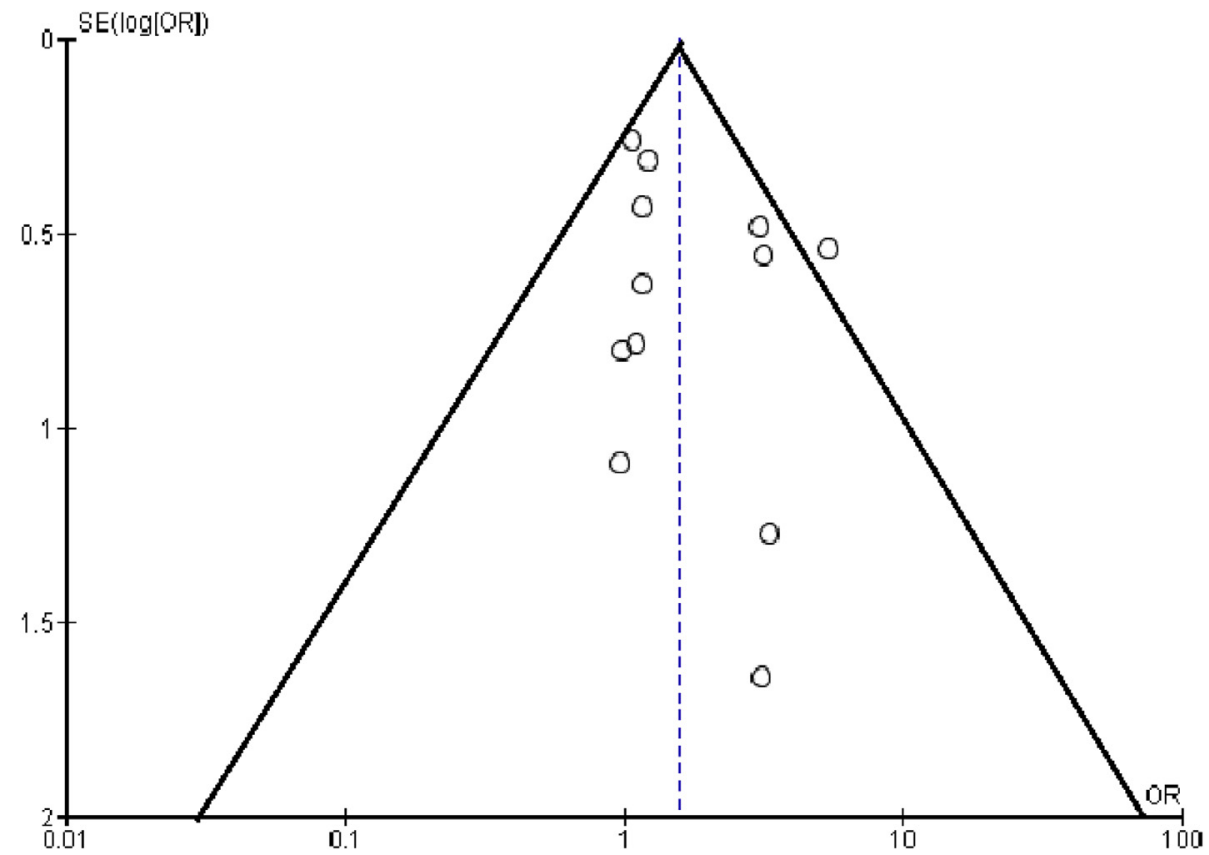

Fig. 4 - Funnel plot showing almost all of the studies with similar results and little heterogeneity. 
Obese Non-Obese Mean Difference

Mean Difference

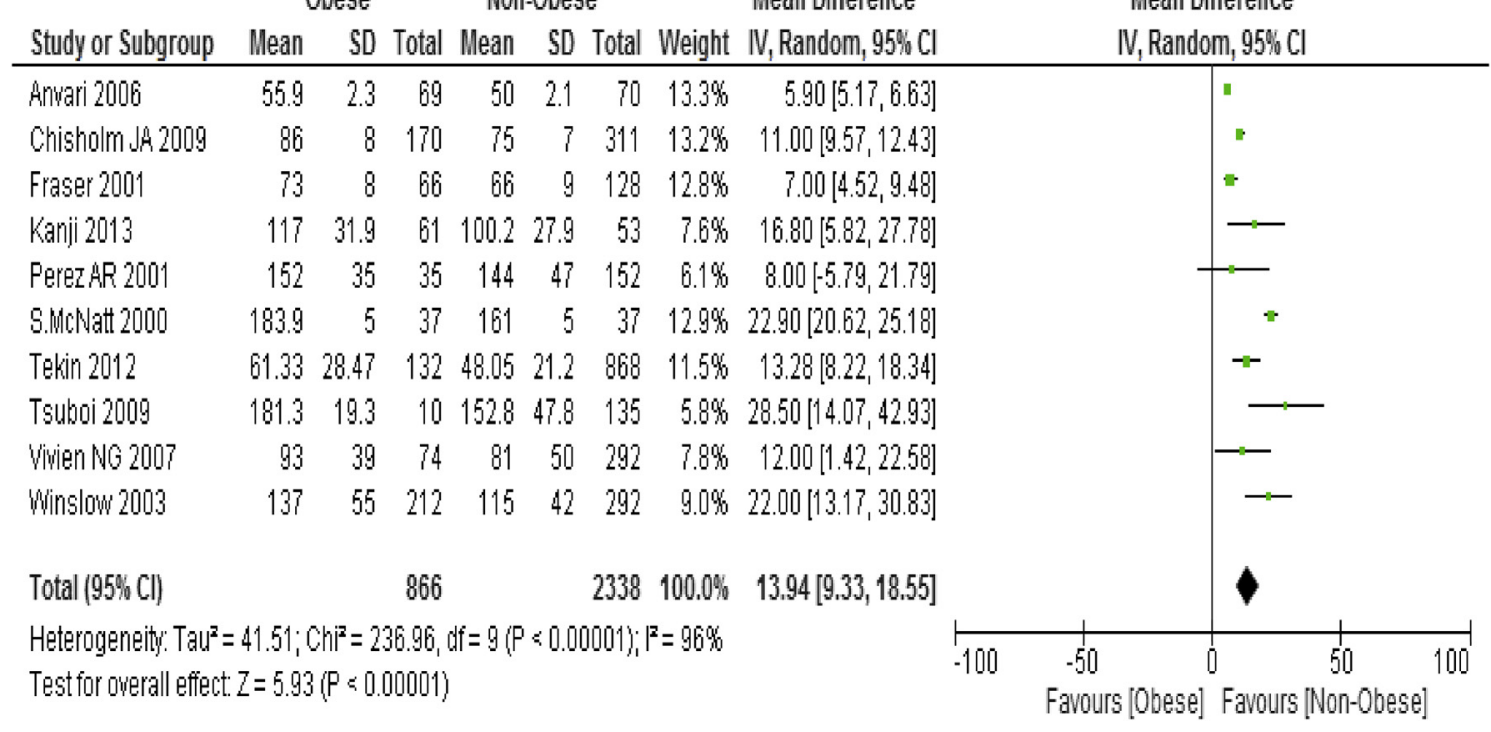

Fig. 5 - Forest Plot of the operative times in Laparoscopic Antireflux surgery for Obese Vs Non-Obese patients. Mean Difference of 13.94 (95\% confidence interval (CI) 9.33-18.55) with severe heterogeneity $\mathrm{I}^{2}=96 \%$. Effect size $\mathrm{Z}=5.93$ which is significant $(p<0.00005)$.

pre-valent among the obese which could be cause of GORD. Obese patients have increased intra-abdominal pressure that displaces the lower oesophageal sphincter and increases the gastro-oesophageal gradient. And vagal abnormalities associated with obesity may cause a higher output of bile and pancreatic enzymes which aggravates problem for obese patients. ${ }^{56}$ And the risk of major complications for obese patients is higher than normal BMI patients following surgery. ${ }^{57}$
The findings of this meta-analysis are significant and in the sense that individual studies (mostly) do not show that there is increased risk of recurrence for obese patients but the collective pooled result of the meta-analysis clearly showed that there is statistically significant increase in recurrence for obese patients compared to non-obese patients.

Studies demonstrate that there is marked improvement in GORD in obese patients after weight loss. ${ }^{58,59}$ Suggesting that

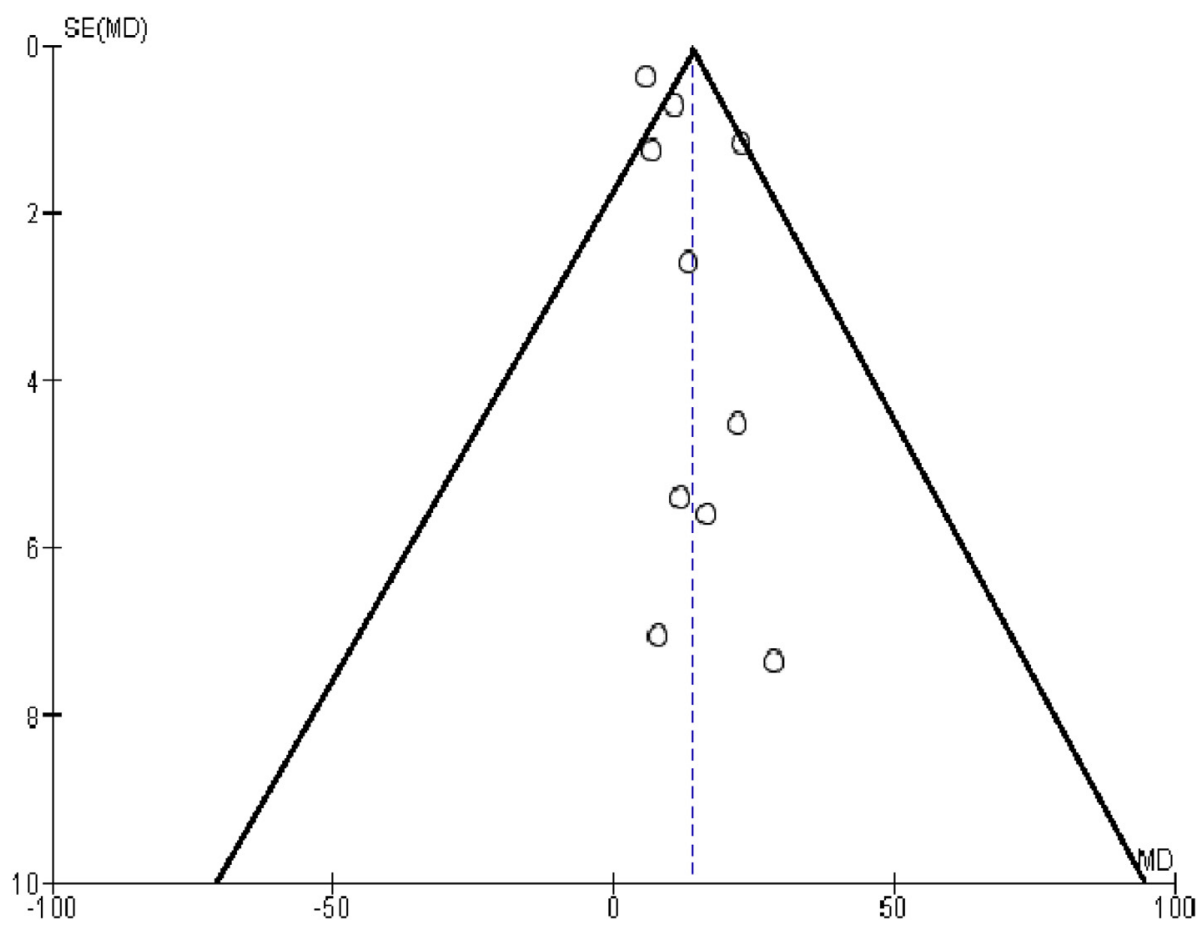

Fig. 6 - Funnel plot showing results of most of the studies for operative time are close to the overall result showing similar results among studies. 
weight reduction should be suggested to patients for improvement in symptoms and it will also reduce the chances of recurrence of symptoms in patients as shown by our metaanalysis. Another alternative could be some bariatric procedures having additional benefit of diminishing symptoms of GORD. ${ }^{60,61}$

One might argue that meta-analysis should be conducted for randomised controlled trials, however due to lack of randomised studies in many areas the meta-analysis is being conducted for non-randomised studies as well and studies have shown that they generally produce estimates of effect similar to those from meta-analyses bases on randomized controlled trials. This is identified by many researchers and led to formation of MOOSE guidelines, recognising that observational studies can be used for meta-analysis. ${ }^{62}$

\section{Summary of evidence}

Individual studies on this topic failed to point to a clear conclusion regarding the effects of obesity on LARS, and no meta-analysis had previously been done. In this metaanalysis, data from 12 studies conducted between 2001 and 2013 was pooled and analysed.

The methodological quality of the studies included in this meta-analysis was good to excellent. The surgical techniques were standardised in all the studies and were explained in detail. Recurrence in obese $(\mathrm{BMI}>30)$ vs non-obese $(\mathrm{BMI}<30)$ patients using random effect model, showed a relative risk of 1.36 (95\%CI 1.08-1.72, $\mathrm{p}<0.05)$ for obese patients. Three articles included in the meta-analysis are conference papers so we leave to readers to decide and interpret results keeping that in mind.

We further analysed the studies to rectify this weakness and included studies which objectively assessed the recurrence and full published articles (See Table 3) and the results showed relative risk of 1.53 (95\% CI 1.01-2.32, $\mathrm{p}=0.05$ ). This shows that there is $53 \%$ more risk of recurrence for obese patients as compared to non-obese patients. The whole of the diamond of forest plot for recurrence favours non-obese with sides ( $95 \%$ confidence interval) on the same side. If we look at the forest plot for recurrence, at first glance, it is obvious that all the studies overlap and there are no outlier results, showing homogenous results in studies. So, whether the recurrence is defined as symptom recurrence or actual acid reflux proven by investigations, in both cases statistically significant, more recurrence was present in obese as compared to non-obese patients.

In the meta-analysis, we also analysed the operative time for the LARS for obese vs non-obese patients. Results showed that obese patients require technically more difficult surgery compared to non-obese patients. This can be easily seen from the mean difference in operative time of $13.94 \mathrm{~min}$ between the two groups. With a significantly longer operative time for the obese group. A similar outcome was seen in laparoscopic colorectal surgery in obese and non-obese patients were seen in a meta-analysis by Zhou et al. ${ }^{63}$ They concluded that obesity is associated with increased conversion rates, operating time and post-operative morbidity in laparoscopic colorectal surgery. This can be explained with the fact that more visceral fat and poorly defined tissue planes lead to more difficult surgery. Similar results were found in our study.

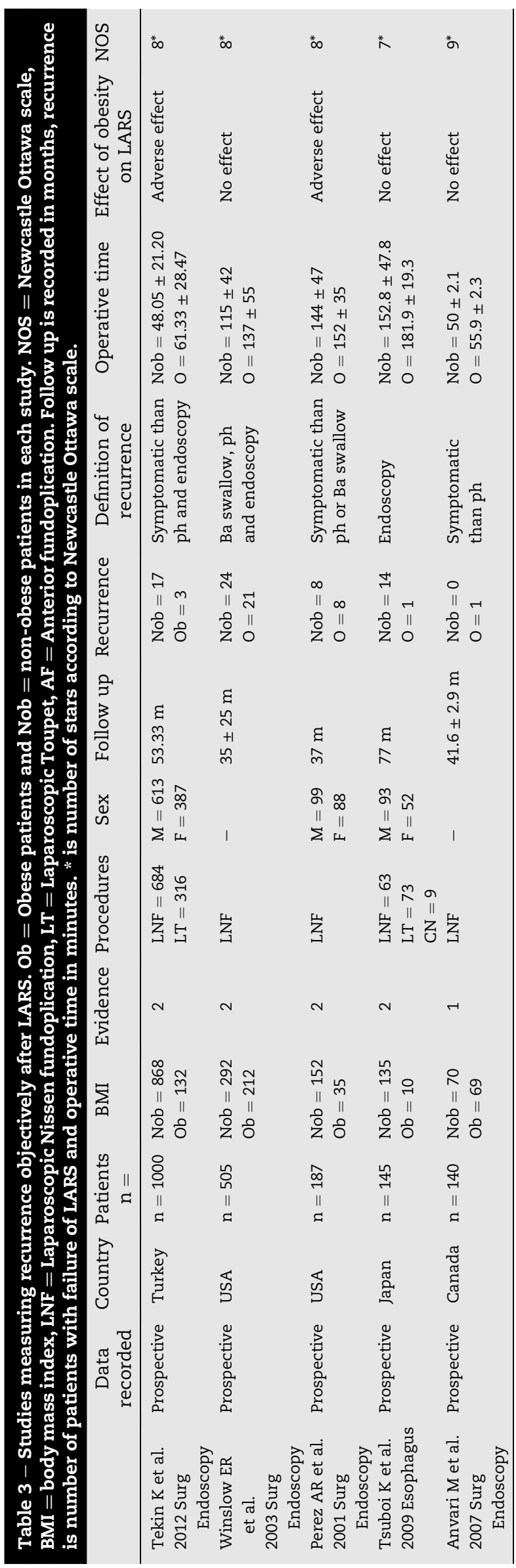


Although the definition of operative time was not defined by the studies, that led to severe heterogeneity of $96 \%$ in the results, all the studies showed longer operative times for the obese vs non-obese patients indicating that surgery in obese patients is technically more challenging.

In conclusion, surgeons should be cautious about offering laparoscopic anti-reflux surgery to obese patients. They should always assess that the severity of the disease is worth taking the risks of the surgery for obese patients and benefits should always overweigh the risks. And if it is offered to obese patients, they should be explained and patient should understand the additional risk of recurrence and longer operative times compared to non-obese patients.

Extensive and exhaustive literature search was done as search strategy was developed with help of librarians. The sensitivity of the search strategy was very high and specificity low which was intentional in order to capture all the available studies. The pooling of the data using predefined data extraction forms and then statistical analysis, showed very low heterogeneity for recurrence indicating that the results are homogenous among the studies. We also used the chisquare test to show that the difference in recurrence between the two groups is statistically significant. It shows a statistically significant relationship between obesity and recurrence after LARS.

\section{Limitations}

In this meta-analysis, operative time of surgery was analysed. It was found that there was huge heterogeneity between the studies. This was because operative time was never explained in detail. It might be the total time spent in the theatre from intubation to extubation, or the actual time of surgery. But as explained before, regardless of this, all the studies showed statistically longer operative times for obese patients.

\section{Conclusion}

In conclusion, the meta-analysis demonstrates that there are significantly increased recurrence rates in obese patients who undergo LARS as compared to non-obese patients, therefore we recommend that patients be informed of this higher likelihood for recurrence as part of the medical and surgical workup. In addition to higher recurrence rates, operative times for obese patients are higher than for non-obese patients, proving that as a procedure, LARS is more demanding in this patient population.

\section{Ethical approval}

Ethical committee approval was not required for the Systematic review and meta-analysis.

\section{Conflicts of interest}

None declared.

\section{Acknowledgements}

The authors also wish to acknowledge contributions to discussions by members of Professorial Surgical Unit, Department of Surgery, The University of Dublin trinity College, Tallaght Hospital, Dublin, Ireland.

\section{R E F E R E N C E S}

1. Ogden CL, Carroll MD, Curtin LR, McDowell MA, Tabak CJ, Flegal KM. Prevalence of overweight and obesity in the United States, 1999-2004. Jama 2006;295(13):1549-55.

2. Kelly T, Yang W, Chen C-S, Reynolds K, He J. Global burden of obesity in 2005 and projections to 2030. Int J Obes 2008;32(9): 1431-7.

3. Locke GR, Talley NJ, Fett SL, Zinsmeister AR, Melton LR. Prevalence and clinical spectrum of gastroesophageal reflux: a population-based study in Olmsted County, Minnesota. Gastroenterology 1997;112(5):1448-56.

4. Dent J, El-Serag H, Wallander MA, Johansson S. Epidemiology of gastro-oesophageal reflux disease: a systematic review. Gut 2005;54(5):710-7.

5. Attwood SE, DeMeester T, Bremner CG, Barlow AP, Hinder RA. Alkaline gastroesophageal reflux: implications in the development of complications in Barrett s columnar-lined lower esophagus. Surgery 1989;106:764-70.

6. Attwood SE, Smyrk TC, DeMeester TR, Mirvish SS, Stein HJ, Hinder RA. Duodenoesophageal reflux and the development of esophageal adenocarcinoma. Surgery 1992;111:503-10.

7. Spechler SJ. Clinical manifestations and esophageal complications of GERD. Am J Med Sci 2003;326(5):279-84.

8. Dent J, Tytgat G. Reflux disease management strategy: initial therapy. Aliment Pharmacol Ther 2003;17(s1):28-52.

9. Lagergren J, Bergstrom R, Nyren O. No relation between body mass and gastro-oesophageal reflux symptoms in a Swedish population based study. Gut 2000;47(1):26-9.

10. Wajed SA, Streets CG, Bremner CG, DeMeester TR. Elevated body mass disrupts the barrier to gastroesophageal reflux. Arch Surg 2001;136(9):1014-9.

11. Hampel H, Abraham NS, El-Serag HB. Meta-analysis: obesity and the risk for gastroesophageal reflux disease and its complications. Ann Intern Med 2005;143(3):199-211.

12. Stein HJ, DeMeester TR. Who benefits from antireflux surgery? World J Surg 1992;16(2):313-9.

13. Palmer $\mathrm{K}$. Review article: indications for anti-reflux surgery and endoscopic anti-reflux procedures. Aliment Pharmacol Ther 2004;20(s8):32-5.

14. Lundell L. Borderline indications and selection of gastroesophageal reflux disease patients: 'is surgery better than medical therapy'? Dig Dis 2014;32(1-2):152-5.

15. Lundell L, Miettinen P, Myrvold H, Pedersen S, Liedman B, Hatlebakk J, et al. Continued (5-year) followup of a randomized clinical study comparing antireflux surgery and omeprazole in gastroesophageal reflux disease. J Am Coll Surg 2001;192(2):172-9.

16. Salminen PT, Hiekkanen HI, Rantala AP, Ovaska JT. Comparison of long-term outcome of laparoscopic and conventional nissen fundoplication: a prospective randomized study with an 11-year follow-up. Ann Surg 2007;246(2):201-6.

17. Lafullarde T, Watson DI, Jamieson GG, Myers JC, Game PA, Devitt PG. Laparoscopic Nissen fundoplication: five-year results and beyond. Arch Surg 2001;136(2):180-4.

18. Broeders JA, Rijnhart-de Jong HG, Draaisma WA, Bredenoord AJ, Smout AJ, Gooszen HG. Ten-year outcome of 
laparoscopic and conventional nissen fundoplication: randomized clinical trial. Ann Surg 2009;250(5):698-706.

19. Broeders J, Mauritz F, Ahmed Ali U, Draaisma W, Ruurda J, Gooszen $\mathrm{H}$, et al. Systematic review and meta-analysis of laparoscopic Nissen (posterior total) versus Toupet (posterior partial) fundoplication for gastro-oesophageal reflux disease. Br J Surg 2010;97(9):1318-30.

20. Tan G, Yang Z, Wang Z. Meta-analysis of laparoscopic total (Nissen) versus posterior (Toupet) fundoplication for gastrooesophageal reflux disease based on randomized clinical trials. ANZ J Surg 2011;81(4):246-52.

21. Luketina R-R, Koch OO, Köhler G, Antoniou SA, Emmanuel K, Pointner R. Obesity does not affect the outcome of laparoscopic antireflux surgery. Surg Endosc 2015;29(6):1327-33.

22. Chisholm JA, Jamieson GG, Lally CJ, Devitt PG, Game PA, Watson DI. HP07 the effect of obesity on the outcome of laparoscopic antireflux surgery. ANZ J Surg 2009;79(s1). A40-A.

23. Moher D, Liberati A, Tetzlaff J, Altman DG, Group P. Preferred reporting items for systematic reviews and meta-analyses: the PRISMA statement. BMJ 2009;339:b2535.

24. Index BM. Body mass index (BMI). 2015. Retrieved from: http:// www.cdc.gov/healthyweight/assessing/bmi/ [Accessed 1 January 2016].

25. Stang A. Critical evaluation of the Newcastle-Ottawa scale for the assessment of the quality of nonrandomized studies in meta-analyses. Eur J Epidemiol 2010;25(9):603-5.

26. Bashir Y, Conlon K. Step by step guide to do a systematic review and meta-analysis for medical professionals. Ir J Med Sci (1971-) 2017:1-6.

27. Wallace BC, Schmid CH, Lau J, Trikalinos TA. Meta-analyst: software for meta-analysis of binary, continuous and diagnostic data. BMC Med Res Methodol 2009;9(1):80.

28. Tekin K, Toydemir T, Yerdel MA. Is laparoscopic antireflux surgery safe and effective in obese patients? Surg Endosc 2012;26(1):86-95.

29. Winslow E, Frisella M, Soper N, Klingensmith M. Obesity does not adversely affect the outcome of laparoscopic antireflux surgery (LARS). Surg Endos 2003;17(12).

30. Perez A, Moncure A, Rattner D. Obesity adversely affects the outcome of antireflux operations. Surg Endosc 2001;15(9):986-9.

31. Tsuboi K, Omura N, Yano F, Kashiwagi H, Kawasaki N, Suzuki Y, et al. Body mass index has no effect on the results of laparoscopic fundoplication in Japanese patients with reflux esophagitis. Esophagus 2009;6(4):237.

32. Anvari M, Bamehriz F. Outcome of laparoscopic Nissen fundoplication in patients with body mass index $>$ or $=35$. Surg Endosc 2006;20(2):230-4.

33. Irino $\mathrm{T}$, Takeuchi H, Ozawa S, Saikawa $\mathrm{Y}$, Oyama T, Hiraiwa K, et al. Age and body mass index: significant predictive factors for successful laparoscopic antireflux surgery. Surg Today 2010;40(12):1137-43.

34. Morgenthal CB, Lin E, Shane MD, Hunter JG, Smith CD. Who will fail laparoscopic Nissen fundoplication? Preoperative prediction of long-term outcomes. Surg Endosc 2007;21(11):1978-84.

35. D'Alessio MJ, Arnaoutakis D, Giarelli N, Villadolid DV, Rosemurgy AS. Obesity is not a contraindication to laparoscopic Nissen fundoplication. J Gastrointest Surg 2005;9(7):949-54.

36. Mohiuddin K, Zahiri HR, Weltz AS, Leydorf SD, Fantry GT Park AE. Role of BMI in determining clinical and quality of life outcomes post laparoscopic antireflux surgery. J Am Coll Surg 2016;4(223):e22.

37. Campos GM, Peters JH, DeMeester TR, Öberg S, Crookes PF, Tan S, et al. Multivariate analysis of factors predicting outcome after laparoscopic Nissen fundoplication.

J Gastrointest Surg 1999;3(3):292-300.
38. Telem DA, Altieri M, Gracia G, Pryor AD. Perioperative outcome of esophageal fundoplication for gastroesophageal reflux disease in obese and morbidly obese patients. Am J Surg 2014;208(2):163-8.

39. O'boyle CJ, Watson DI, DeBeaux AC, Jamieson GG. Preoperative prediction of long-term outcome following laparoscopic fundoplication. ANZ J Surg 2002;72(7):471-5.

40. Jones K. Obesity and antireflux surgery. Surg Endosc 2002;16(9):1380.

41. Perez A, Moncure A, Rattner D, editors. Obesity is a major cause of failure for both transabdominal and transthoracic antireflux operations. Gastroenterology. 1600 John F Kennedy Boulevard, STE 1800, Philadelphia, PA 19103-2899 USA: WB Saunders CoElsevier Inc; 1999.

42. Daigle CR, Boules M, Corcelles R, Davis M, Chang J, Liu M, et al. 475 natural history of primary fundoplication in the obese: a multicenter study. Gastroenterology 2015;148(4):S-1109.

43. McNatt SS, Smith CD, Hunter JG, Galloway KG. Morbid obesity does not predict a poor outcome after laparoscopic antireflux surgery. Gastroenterology 2000;118(4):A1033.

44. Kanji Aliyah, Funk Luke, Suzo Andrew, Vargo James, Scott Melvin W, Perry Kyle A. Laparoscopic Nissen fundoplication effectively controls refractory reflux symptoms in obese and non-obese patients: patient symptoms and satisfaction at 1 year. Surg Endosc 2013;27:S377.

45. Ng VV, Booth MI, Stratford JJ, Jones L, Sohanpal J, Dehn TC. Laparoscopic anti-reflux surgery is effective in obese patients with gastro-oesophageal reflux disease. Ann R Coll Surg Engl 2007;89(7):696-702.

46. Hahnloser D, Schumacher M, Cavin R, Cosendey B, Petropoulos P. Risk factors for complications of laparoscopic Nissen fundoplication. Surg Endosc 2002;16(1):43-7.

47. Fraser J, Watson D, O'boyle C, Jamieson G. Obesity and its effect on outcome of laparoscopic Nissen fundoplication. Dis Esophagus 2001;14(1):50-3.

48. Kappaz G, Sallum RA, Szachnowicz S, Sampaio AL, Cecconello I. Postoperative Bmi as risk factor for patient satisfaction after laparoscopic Nissen fundoplication: preliminary report. Dis Esophagus 2010;23:89A.

49. Douketis JD. Body weight classification. Can Med Assoc J 2005;172(10):1274-5.

50. Fasol R, Schindler M, Schumacher B, Schlaudraff K, Hannes W, Seitelberger R, et al. The influence of obesity on perioperative morbidity: retrospective study of 502 aortocoronary bypass operations. Thorac Cardiovasc Surg 1992;40(03):126-9.

51. Flancbaum Louis, Choban Patricia S. Surgical implications of obesity. Annu Rev Med 1998;49(1):215-34.

52. Foley K, Lee RB. Surgical complications of obese patients with endometrial carcinoma. Gynecol Oncol 1990;39(2):171-4.

53. Postlethwait RW, Johnson WD. Complications following surgery for duodenal ulcer in obese patients. Arch Surg 1972;105(3):438-40.

54. Bailey MB, Davenport DL, Vargas HD, Evers BM, McKenzie SP. Longer operative time: deterioration of clinical outcomes of laparoscopic colectomy versus open colectomy. Dis Colon Rectum 2014;57(5):616-22.

55. Scheer A, Martel G, Moloo H, Sabri E, Poulin EC, Mamazza J, et al. Laparoscopic colon surgery: does operative time matter? Dis Colon Rectum 2009;52(10):1746-52.

56. Barak N, Ehrenpreis E, Harrison J, Sitrin M. Gastrooesophageal reflux disease in obesity: pathophysiological and therapeutic considerations. Obes Reu 2002;3(1):9-15.

57. Schwandner O, Farke S, Schiedeck T, Bruch H-P. Laparoscopic colorectal surgery in obese and nonobese patients: do differences in body mass indices lead to different outcomes? Surg Endosc 2004;18(10):1452-6. 
58. Fraser-Moodie C, Norton B, Gornall C, Magnago S, Weale A, Holmes G. Weight loss has an independent beneficial effect on symptoms of gastro-oesophageal reflux in patients who are overweight. Scand J Gastroenterol 1999;34(4):337-40.

59. Mathus-Vliegen E, Tytgat G. Gastro-oesophageal reflux in obese subjects: influence of overweight, weight loss and chronic gastric balloon distension. Scand J Gastroenterol 2002;37(11):1246-52.

60. Rrezza E, Ikramuddin S, Gourash W, Rakitt T, Kingston A, Luketich J, et al. Symptomatic improvement in gastroesophageal reflux disease (GERD) following laparoscopic Roux-en-Y gastric bypass. Surg Endosc 2002;16(7):1027-31.
61. Nelson LG, Gonzalez R, Haines K, Gallagher SF, Murr MM. Amelioration of gastroesophageal reflux symptoms following Roux-en-Y gastric bypass for clinically significant obesity. Am Surg 2005;71(11):950-4.

62. Stroup DF, Berlin JA, Morton SC, Olkin I, Williamson GD, Rennie D, et al. Meta-analysis of observational studies in epidemiology: a proposal for reporting. Jama 2000;283(15):2008-12.

63. Zhou Y, Wu L, Li X, Wu X, Li B. Outcome of laparoscopic colorectal surgery in obese and nonobese patients: a metaanalysis. Surg Endosc 2012;26(3):783-9. 